\title{
OLHANDO A SAÚDE DO HOMEM
}

\author{
LOOKING AT MEN'S HEALTH
}

\author{
Cindy Karina Soares de Oliveira ${ }^{1}$ \\ Arthur de Abrantes Silva \\ Ankilma do Nascimento Andrade Feitosa \\ Geane Silva Oliveira \\ Renata Lívia Silva Fonsêca Moreira ${ }^{2}$
}

RESUMO: Tem por objetivo analisar através da literatura o conhecimento da população masculina sobre a Política Nacional de Atenção Integral à Saúde do Homem (PNAISH). O estudo trata-se de uma revisão integrativa, realizada nos meses de fevereiro a abril de 2019 e que tem como pergunta norteadora: Qual o conhecimento do público masculino acerca da Política Nacional de Atenção Integral à Saúde do Homem (PNAISH)? O levantamento bibliográfico foi realizado pela Internet, por meio das bases de dados LILACS (Literatura Latino-Americana em Ciências de Saúde) e SciELO (Scientific Electronic Library Online). Para a busca dos artigos, foi feito o cruzamento dos seguintes descritores: "Saúde do Homem", "Política Pública" e "Conhecimento". Após a pesquisa e aplicação dos filtros, restaram seis artigos para compor a pesquisa. Percebe-se que, embora exista a Política Nacional de Atenção Integral à Saúde do Homem (PNAISH) há 10 anos, ainda existe a resistência do público masculino e a ausência de estratégias para tornar a política conhecida executada nos serviços de saúdes, especialmente na atenção básica. Observa-se o desconhecimento do público masculino acerca da sua política e a urgência em conscientizar os homens da importância do cuidado com a sua saúde, tendo em vista o aumento da morbimortalidade da sua classe.

DESCRITORES: Saúde do Homem; Política Pública; Conhecimento.

ABSTRACT: the objective was to analyze, through the literature, the knowledge of the male population about the National Policy for Comprehensive Health Care for Men (PNAISH - Política Nacional de Atenção Integral à Saúde do Homem). The study is an integrative review, conducted from February to April 2019, with the

\footnotetext{
${ }^{1}$ Discente do curso Bacharelado em Enfermagem da Faculdade Santa Maria (FSM), Cajazeiras - PB. E-mail: cindy-karina@outlook.com.

${ }^{2}$ Docente da Faculdade Santa Maria (FMS). Enfermeira pela Universidade Federal da Paraíba (UFPB) Especialista em Saúde Pública pela FACISA. Mestre em Enfermagem pela Universidade Federal da Paraíba (UFPB). Doutora pela Faculdade de Ciências Médicas Santa Casa de São Paulo FCMSP.
} 
following guiding question: What is the knowledge of the male public about the National Policy for Comprehensive Health Care for Man (PNAISH - Politica Nacional de Atenção Integral à Saúde do Homem)? The bibliographical survey was performed through the Internet, through the LILACS (Latin American Literature in Health Sciences) and SciELO (Scientific Electronic Library Online) databases. The search for the articles cross-referenced the following descriptors: "Men's Health", "Public Policy" and "Knowledge". After the research and application of the filters, six articles were selected to compose the sample. Although the National Policy for Comprehensive Health Care for Men (PNAISH) has existed for 10 years, the male public still shows resistance and there is lack of strategies to publicize the policy at health services, especially in the basic attention. The male public are unaware of their policy and there is urgency to make men aware of the importance of taking care of their health, in view of the increased morbidity and mortality in their class.

DESCRIPTORS: Men's Health; Public policy; Knowledge. 


\section{INTRODUÇÃO}

Há algum tempo, a saúde brasileira tem avançado no tocante ao conhecimento, acolhimento e acessibilidade. O Sistema Único de Saúde (SUS) garante a saúde universal com atendimento igualitário, que vem se fortalecendo através de políticas públicas e uma das maiores consolidações foi a implementação da Estratégia Saúde da família (ESF) através do Ministério da Saúde (MS) e das Secretarias Municipais e Estaduais. Apesar da complexidade na saúde brasileira, ainda sim, são notórios os grandes avanços (AGUIAR, SANTANA, SANTANA, 2015).

A Estratégia de Saúde da Família (ESF) tem a visibilidade de reorganizar os serviços do SUS na Atenção Básica ( $A B)$, através de uma equipe multidisciplinar que acolhe, reorienta e ainda intervém de forma qualificada em fatores que trazem risco à vida do usuário (SILVA, BARBOSA, HORTALE, 2016).

Compreendendo que a atenção básica $(A B)$ tem como objetivo a promoção de saúde e prevenção de doença, a qual surgiu de forma organizada e necessária, políticas públicas voltadas especificamente para o público feminino, idoso, adolescente e criança, porém com pouca visibilidade para a saúde do homem, fato este que torna evidente a invisibilidade do público masculino (MOREIRA, GOMES, RIBEIRO, 2016).

Moreira, Carvalho (2016) afirmam que, na invisibilidade masculina, notou-se que o homem adentra no serviço de saúde, geralmente em busca de um tratamento tardio, o qual a demanda da atenção e o cuidado necessário só devem ser prestados em hospitais de média e alta complexidade, resultando no aumento de morbimortalidade e evidenciando uma prevenção de doença e promoção de saúde fragilizada, finalizando, então, no alto custo da assistência do SUS, já que o número de internamento de homens é bem maior, tornando-se necessária a criação de uma Política Pública destinada ao meio masculino. 
Diante dos fatos acima, em 2008, foi lançada, no Brasil, a Política Nacional de Atenção Integral à Saúde do Homem (PNAISH), que visa a atender ao público masculino a partir dos 20 aos 59 anos, com objetivo de introduzir o homem no serviço de saúde de forma qualificada, através de planejamentos de ações que promovam a assistência, articulando novas maneiras de trazer o homem ao serviço de saúde. Ao mesmo tempo, é necessário romper as barreiras e as questões de gênero, bem como a ideia de invulnerabilidade que geraram ao longo do tempo nessa população de forma que venha refletir, assim, na diminuição do alto e considerável índice de morbimortalidade dos homens e, ainda, a diminuição no custeio da saúde dos mesmos (CARNEIRO et al, 2016).

O Ministério da Saúde (MS) (2018) aponta que os homens morrem mais que mulheres geralmente por causas externas. A diferença entre o comportamento de risco/proteção do homem e da mulher só reforça mais a necessidade de atenção e planejamento a esse público masculino. Sua resistência através da educação vinda do fator de gênero inserida na sociedade leva-o a acreditar na ideia de que "homem não precisa buscar ajuda", "homem é forte e resistente", "homem sozinho é capaz", tornando desconhecidos seus direitos e ainda a busca por saúde de forma tardia.

A Política Nacional de Atenção Integral à Saúde do Homem (PNAISH) é uma resposta à gravidade da vulnerabilidade à morbimortalidade e a doenças crônicas e graves que acometem o público masculino, público este que retarda a busca pelos serviços de saúde, exaltando, ainda, a resistência para adesão de prevenção de doença e promoção de saúde, bem como as propostas terapêuticas com diferença exorbitante quando comparado a outros públicos (CHAKORA, 2014).

De acordo com Ministério da Saúde (MS), na cartilha publicada em 2009, o objetivo desta política é promover a melhoria nas condições de saúde pública da comunidade masculina, de modo a contribuir significantemente nos cinco eixos que compõem a PNAISH, sendo eles: acesso e acolhimento, saúde sexual e reprodutiva, paternidade e cuidado, doenças prevalentes na população masculina e a prevenção de violência e acidentes. É ainda necessário reorganizar os serviços de saúde, promovendo ações que atendam a este público de forma humanizada e lançando um olhar especial dos profissionais para as necessidades do homem de forma que venha a diminuir o número de agravos e tornar o ambiente favorável a este público. 
Diante de 10 anos do lançamento da Política Nacional de Atenção Integral à Saúde do Homem, despertou-se a inquietação enquanto pesquisadora sobre o conhecimento da população masculina sobre a sua política.

\section{METODOLOGIA}

O estudo trata-se de uma revisão integrativa, descrita por Amaral et al. (2017) como sendo a junção e síntese de resultados de diversas pesquisas sob determinado tema, com a inclusão de métodos diversos e tendo como principal objetivo fornecer e direcionar as práticas, baseando-se nas evidências científicas.

Oliveira et al. (2013) afirmam que a revisão integrativa exige os mesmos padrões de rigor, clareza e replicação utilizada nos estudos primários e está dividida em seis etapas: delimitação da questão de pesquisa; estabelecimento dos critérios de inclusão/exclusão para a seleção dos estudos a serem analisados; definição das informações a serem extraídas dos estudos selecionados; avaliação dos estudos incluídos na revisão integrativa; análise dos dados e interpretação dos resultados; e apresentação da síntese da revisão.

A questão norteadora do estudo é: Qual o conhecimento do público masculino acerca da Política Nacional de Atenção Integral à Saúde do Homem (PNAISH)?

O levantamento bibliográfico foi realizado pela Internet, por meio das bases de dados LILACS (Literatura Latino-Americana em Ciências de Saúde) e SciELO (Scientific Electronic Library Online). Para a busca dos artigos, foi feito o cruzamento dos seguintes descritores: "saúde do homem" "política pública" e "conhecimento". A coleta de dados ocorreu nos meses de fevereiro a abril de 2019.

Os critérios utilizados para a seleção da amostra foram: artigos que apresentavam a temática do estudo, em português, disponibilizados em texto completo, de acesso gratuito, publicados e indexados em periódicos nacionais nos referidos bancos de dados no ano de 2016 a 2018. Os critérios de exclusão foram: artigos incompletos relacionados à pesquisa metodológica ou que não estivessem 
disponibilizados em língua portuguesa, bem como as revisões de literatura, resumos, teses e dissertações; além de artigos que não estivessem entre o período determinado nos critérios de inclusão.

Foi feita a identificação dos artigos a partir do cruzamento dos três descritores, aplicando os critérios de inclusão e exclusão. Em seguida, foi realizada a análise dos dados, a discussão e, por fim, a apresentação da síntese da revisão.

Após uma pesquisa exaustiva nas bases de dados LILACS (Literatura LatinoAmericana em Ciências de Saúde) e SciELO (Scientifi Electronic Library Online), obtiveram-se os seguintes resultados:

Figura 01: Resultados dos artigos encontrados na Lilacs e Scielo.
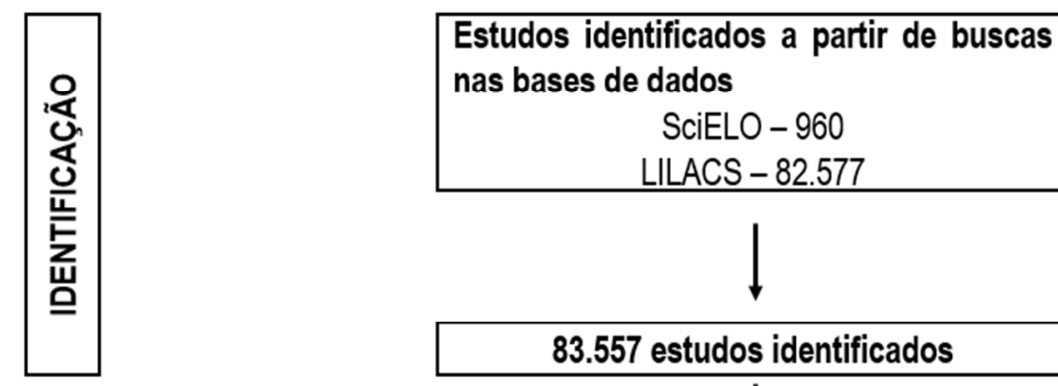

SCIELO - 960

LILACS -82.577
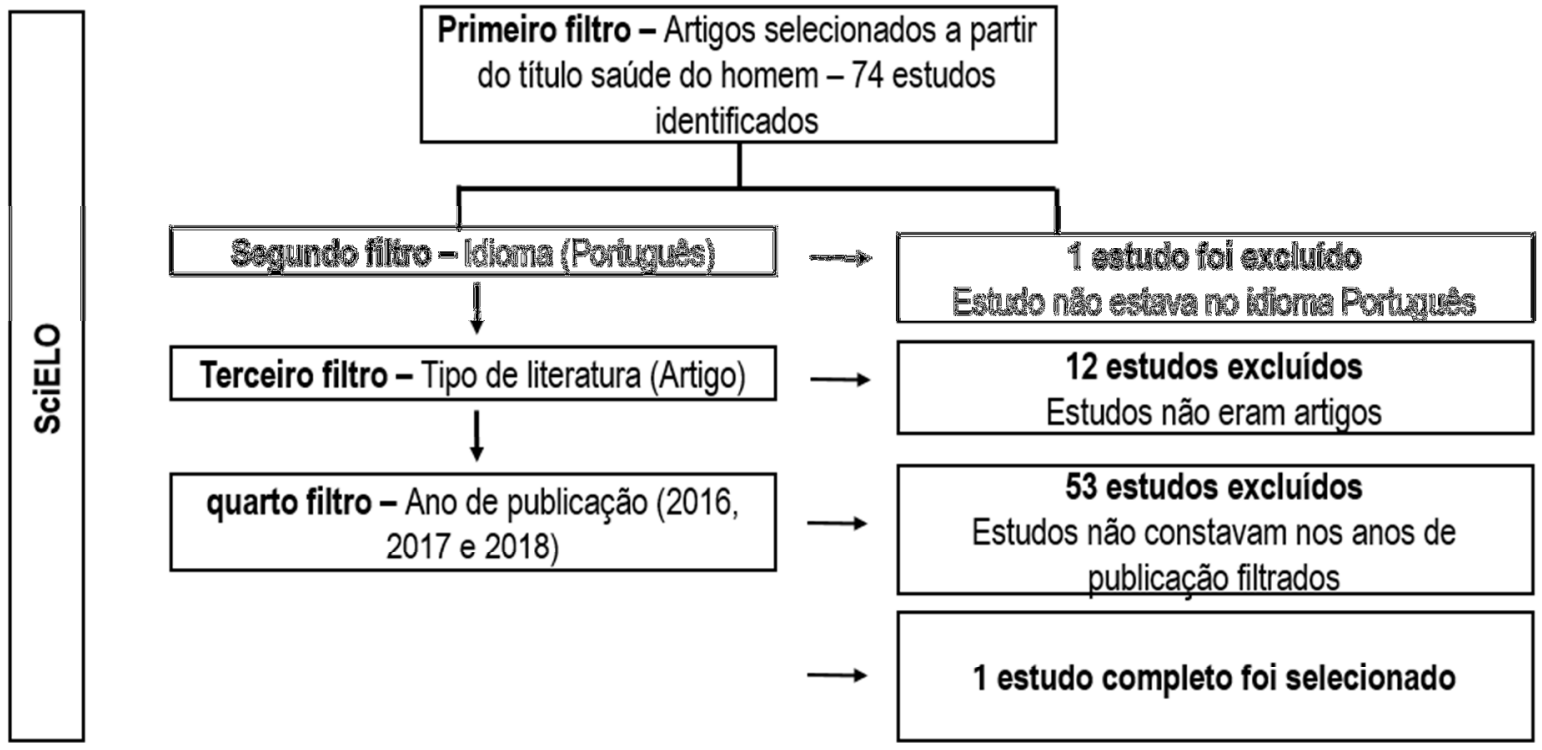

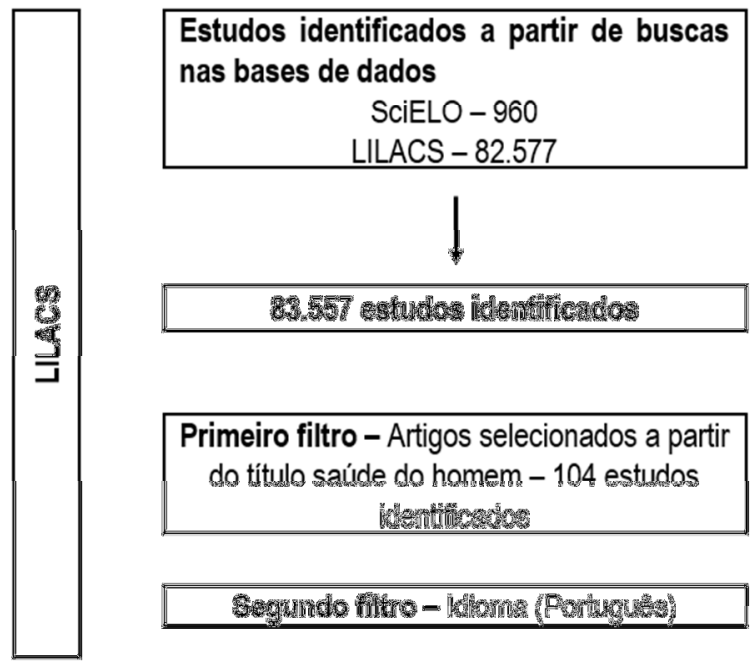

Primeiro filtro - Artigos selecionados a partir do título saúde do homem - 104 estudos

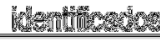

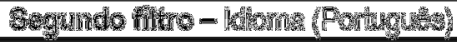

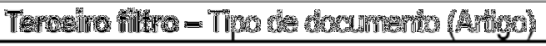

quarto filtro - Texto completo

quinto filtro - Ano de publicação (2016, 2017 e 2018)

Fonte: Dados da pesquisa (2019).

\section{RESULTADOS E DISCUSSÃO}

$\mathrm{Na}$ presente revisão integrativa, realizou-se a análise de seis artigos que atenderam aos critérios de inclusão inicialmente estabelecidos. No decorrer deste texto, serão apresentados os resultados obtidos nesta pesquisa. 
$\mathrm{Na}$ Tabela 1, estão descritas as especificações de cada artigo selecionado para a realização desta revisão de acordo com: título; autor/ano; objetivos; principais resultados; e base de dados/periódico. No que diz respeito aos periódicos onde foram publicados os artigos listados nessa pesquisa, apenas um não é brasileiro, trata-se da Revista Cubana de Enfermería.

Já na questão do período das publicações, foi observado que a maioria das publicações aconteceu nos anos de 2016 e 2017, e, no ano de 2018, não houve nenhuma publicação.

Quadro 1- Caracterização dos artigos selecionados para revisão.

\begin{tabular}{|c|c|c|c|c|}
\hline Título & $\begin{array}{c}\text { Autor/A } \\
\text { no }\end{array}$ & Objetivos & Principais resultados & $\begin{array}{l}\text { Base de } \\
\text { Dados I } \\
\text { Periódico }\end{array}$ \\
\hline $\begin{array}{l}\text { Encontros e } \\
\text { desencontros } \\
\text { entre a } \\
\text { saúde do } \\
\text { homem, a } \\
\text { promoção da } \\
\text { paternidade } \\
\text { participativa } \\
\text { e a saúde } \\
\text { sexual e } \\
\text { reprodutiva } \\
\text { na atenção } \\
\text { básica. }\end{array}$ & $\begin{array}{l}\text { Ribeiro } \\
\text { et. } \\
\text { al./2017. }\end{array}$ & $\begin{array}{l}\text { Objetivamos } \\
\text { problematizar } \\
\text { três ações } \\
\text { desenvolvidas } \\
\text { em unidades } \\
\text { básicas de saúde } \\
\text { de três } \\
\text { municípios de } \\
\text { regiões } \\
\text { brasileiras } \\
\text { distintas, } \\
\text { voltadas para a } \\
\text { saúde r do } \\
\text { homem, a } \\
\text { promoção da } \\
\text { paternidade } \\
\text { participativa } \\
\text { comprometida } \\
\text { com o cuidado e } \\
\text { a saúde sexual e } \\
\text { reprodutiva. }\end{array}$ & $\begin{array}{l}\text { Dentre outros aspectos, concluímos } \\
\text { que os homens percebem que as } \\
\text { questões de gênero ainda são } \\
\text { impeditivos para essa inserção, assim } \\
\text { como a organização do próprio } \\
\text { sistema; e que as ações analisadas } \\
\text { se organizam de forma estanque e } \\
\text { fragmentada, atuando sobre aspectos } \\
\text { isolados da saúde masculina, não } \\
\text { contemplando o princípio da } \\
\text { integralidade e dificultando a } \\
\text { promoção do vínculo desses homens } \\
\text { ao sistema pela atenção primária. }\end{array}$ & $\begin{array}{l}\text { Lilacs I } \\
\text { Physis: } \\
\text { Revista de } \\
\text { Saúde } \\
\text { Coletiva. }\end{array}$ \\
\hline $\begin{array}{l}\text { Atenção à } \\
\text { saúde do } \\
\text { homem: } \\
\text { análise da } \\
\text { sua } \\
\text { resistência } \\
\text { na procura } \\
\text { dos serviços } \\
\text { de saúde. }\end{array}$ & $\begin{array}{l}\text { Teixeira } \\
\text { e Cruzl } \\
2016 .\end{array}$ & $\begin{array}{lr}\text { ldentificar } & \text { as } \\
\text { causas } & \text { que } \\
\text { levam } & \text { os } \\
\text { homens } & \text { a } \\
\text { desenvolverem } & \\
\text { resistência r no } \\
\text { cuidado da } & \text { sua } \\
\text { saúde, e } & \text { saber } \\
\text { se } & \text { as } \\
\text { concepções de } \\
\text { gênero trazem } \\
\text { obstáculos à } \\
\text { procura raos } \\
\text { serviços } & \text { de } \\
\text { saúde. } & \end{array}$ & $\begin{array}{l}\text { Os homens são resistentes no } \\
\text { cuidado da sua saúde devido a } \\
\text { sentimentos de medo, vergonha, e } \\
\text { por causas comportamentais como a } \\
\text { impaciência, o descuido, prioridades } \\
\text { de vida, e ainda com as questões } \\
\text { relacionadas com a forma de } \\
\text { organização dos serviços de saúde. } \\
\text { Observou-se que os fatores ligados } \\
\text { ao gênero exercem forte influência, } \\
\text { muitas vezes até como obstáculo. }\end{array}$ & $\begin{array}{l}\text { Lilacs/ } \\
\text { Revista } \\
\text { Cubana de } \\
\text { Enfermería. }\end{array}$ \\
\hline
\end{tabular}




\begin{tabular}{|c|c|c|c|c|}
\hline $\begin{array}{l}\text { Políticas } \\
\text { públicas de } \\
\text { atenção } \\
\text { integral a } \\
\text { saúde do } \\
\text { homem: } \\
\text { desafios para } \\
\text { a } \\
\text { enfermagem. }\end{array}$ & $\begin{array}{l}\text { Ferreira } \\
\text { et. al./ } \\
2016 \text {. }\end{array}$ & $\begin{array}{l}\text { Avaliar o } \\
\text { conhecimento, } \\
\text { as práticas e } \\
\text { crenças dos } \\
\text { trabalhadores do } \\
\text { sexo masculino } \\
\text { acerca de sua } \\
\text { saúde. }\end{array}$ & $\begin{array}{l}\text { Os depoimentos analisados levaram } \\
\text { a construção de duas categorias: A } \\
\text { Política Pública de Atenção Integral a } \\
\text { Saúde do Homem apresentada como } \\
\text { ferramenta primordial na promoção } \\
\text { da saúde e prevenção de doenças; e } \\
\text { a disseminação dessa política, } \\
\text { alertando sobre riscos e doenças. } \\
\text { Evidenciou-se que os homens ainda } \\
\text { assumem o papel de provedor da } \\
\text { família e optam por não faltar ao } \\
\text { trabalho, mediante uma consulta e } \\
\text { possuem desconhecimento da } \\
\text { Política Pública de Atenção Integral à } \\
\text { Saúde do Homem. }\end{array}$ & $\begin{array}{l}\text { Lilacs/ } \\
\text { Revista } \\
\text { Enfermage } \\
\text { m UERJ. }\end{array}$ \\
\hline $\begin{array}{l}\text { Atenção } \\
\text { integral à } \\
\text { saúde } \\
\text { homem: } \\
\text { desafio } \\
\text { atenção } \\
\text { básica. }\end{array}$ & $\begin{array}{l}\text { Carneiro } \\
\text { et. al./ } \\
2016 \text {. }\end{array}$ & $\begin{array}{l}\text { Compreender a } \\
\text { percepção dos } \\
\text { profissionais de } \\
\text { saúde sobre a } \\
\text { Política Nacional } \\
\text { de } \\
\text { Atenção Integral } \\
\text { à Saúde do } \\
\text { Homem } \\
\text { (PNAISH). }\end{array}$ & $\begin{array}{l}\text { Ficou evidenciado que os } \\
\text { profissionais entrevistados não } \\
\text { conhecem a PNAISH e poucos } \\
\text { compreendem a sua importância para } \\
\text { o acompanhamento integral do } \\
\text { homem. Há várias dificuldades para a } \\
\text { implementação da PNAISH, tais } \\
\text { como a deficiência de recursos } \\
\text { materiais e humanos, e ainda a falta } \\
\text { de interesse do próprio homem em } \\
\text { cuidar da sua saúde. }\end{array}$ & $\begin{array}{l}\text { Lilacs/ } \\
\text { Revista } \\
\text { Brasileira } \\
\text { em } \\
\text { Promoção } \\
\text { da Saúde. }\end{array}$ \\
\hline $\begin{array}{ll}\text { O acesso do } \\
\text { homem } & \text { ao } \\
\text { serviço } & \text { de } \\
\text { saúde } & \text { na } \\
\text { atenção } & \\
\text { primária. } & \end{array}$ & $\begin{array}{l}\text { Solano } \\
\text { et. al.I } \\
2017 \text {. }\end{array}$ & $\begin{array}{lr}\text { Investigar } & \text { os } \\
\text { aspectos } & \text { que } \\
\text { influenciam no } & \text { no } \\
\text { acesso } & \text { do } \\
\text { homem ao } & \text { ao } \\
\text { serviço de saúde } \\
\text { da atenção } \\
\text { primária. }\end{array}$ & $\begin{array}{l}\text { Os usuários expressaram pouco } \\
\text { investimento na organização do } \\
\text { serviço numa perspectiva de gênero, } \\
\text { reforçando o senso comum de que os } \\
\text { homens não são usuários da atenção } \\
\text { primária, tendo ainda uma ideologia } \\
\text { subsidiada pelo patriarcado. }\end{array}$ & $\begin{array}{l}\text { Lilacs/ } \\
\text { Revista } \\
\text { Online de } \\
\text { Pesquisa. }\end{array}$ \\
\hline $\begin{array}{l}\text { E agora o } \\
\text { homem } \\
\text { vem? } \\
\text { Estratégias } \\
\text { de atenção à } \\
\text { saúde dos } \\
\text { homens. }\end{array}$ & $\begin{array}{l}\text { Moreira } \\
\text { et. al./ } \\
2016 \text {. }\end{array}$ & $\begin{array}{l}\text { O objetivo central } \\
\text { é analisar as } \\
\text { estratégias de } \\
\text { atenção à saúde } \\
\text { dos homens } \\
\text { segundo a ótica } \\
\text { de profissionais } \\
\text { de saúde. }\end{array}$ & $\begin{array}{l}\text { Na literatura, observa-se um forte } \\
\text { destaque acerca da ausência dos } \\
\text { homens na atenção à saúde, com } \\
\text { sistematização teórica, reflexão crítica } \\
\text { e contribuições sobre essas ideias. } \\
\text { Não queremos ignorar o fato de que } \\
\text { não temos ainda uma mudança } \\
\text { significativa nesse cenário, } \\
\text { mantendo-se a necessidade de } \\
\text { enfrentar seus desafios. Desejamos, } \\
\text { em um tempo histórico ainda em } \\
\text { curso, possibilitar provocações sobre } \\
\text { a, ainda que pouca, presença dos } \\
\text { homens nos serviços de saúde, } \\
\text { destacando o que essa visibilidade já } \\
\text { propicia em termos de avanços e } \\
\text { aprendizagens para os profissionais. } \\
\text { Contudo, queremos produzir um } \\
\text { deslocamento de ideias bastante } \\
\text { comuns e de um repertório muito } \\
\text { fortemente evocado sobre a ausência } \\
\text { dos homens nos serviços de saúde, } \\
\text { tentando tornar mais visíveis as } \\
\text { ações já realizadas com esses }\end{array}$ & $\begin{array}{l}\text { Scielo/ } \\
\text { Cadernos } \\
\text { de Saúde } \\
\text { Pública. }\end{array}$ \\
\hline
\end{tabular}


sujeitos.

Fonte: Autora (2019).

Diante da leitura minuciosa e da análise dos resultados das respectivas pesquisas, tornou-se possível estabelecer o seguinte tema:

Desconhecimento da população masculina quanto a Politica Nacional de Atenção Integral a Saúde do Homem como resultado da não implementação da Estratégia Saúde da Família (ESF) pelos profissionais

Moreira et. al. (2016), nos seus estudos, constataram que o homem faz pouco uso dos serviços de saúde, especialmente no que diz respeito à atenção básica. $A$ Política Nacional de Atenção Integral à Saúde do Homem (PNAISH) também relata essa afirmação, o que torna ainda mais difícil o conhecimento e funcionalidade da política no meio masculino. De acordo com os mesmos autores, uma das causas para o homem não utilizar esse serviço é a ausência de reconhecimento da diversidade de homens, que ocorre por parte dos gestores e dos profissionais da saúde, ocasionando a dificuldade de implantação da política.

De acordo com Ferreira et al. (2016), outro fator que contribui para a pouca demanda de homens que procuram os serviços de saúde pública é a falta de informação nos meios de comunicação, e é justamente através dessa comunicação que é possível lançar a política em meio ao publico masculino. Portanto, há ausência de informações e propagandas voltadas para este público, especialmente sobre a necessidade do auto cuidado, planejamento familiar e quanto a seus direitos; no entanto, quando existem, não conseguem atender às expectativas masculinas $e$, uma vez distantes e leigos sobre o quesito saúde e fortalecidos pela sociedade sobre a ideia de invulnerabilidade, são incapazes de compreender sua política fora de comunicação. Sendo assim, Moreira et. al. (2016) consideram que os serviços de saúde possuem o costume de tornar o homem invisível, ocultando suas demandas e carências, portanto, partindo da atenção primária no setor da saúde, esta, por sua vez, não coloca o homem como fator principal. 
CARNEIRO et. al. (2016) afirmam que, quando a PNAISH foi lançada em 2008, buscava atender o público masculino com o objetivo de desenvolver melhores condições de saúde para os homens, por meio de ações de prevenção, promoção e proteção básica à saúde. Despertar e sensibilizar tanto o público masculino quanto os profissionais de saúde sobre a importância do cuidar da saúde do homem é um dos propósitos dessa política. Por outro lado, para Arruda et. al. (2017), cuidados e práticas alternativas colocando o homem como protagonista devem ser adotadas para assegurar que haja o acesso do público masculino à saúde. Considerar a opinião do próprio usuário a respeito da qualidade do serviço prestado é fundamental para que haja uma evolução nesse quesito. Atender as necessidades desse usuário facilitaria o serviço e, consequentemente, aumentaria o uso por parte deste público.

A população masculina está entre a produção de riscos à saúde, pois não procura assistência à saúde, acreditando que este tipo de cuidado remete à fragilidade, associando a mulheres, crianças e idosos, e assim, acarretando aumento nos gastos do SUS, além de sofrimento físico e emocional do paciente e dos familiares. (ARRUDA et. al. 2017).

Apoiando-se em Moreira et al. (2016), pode-se dizer que, quando o profissional torna-se íntimo do homem, descobre que, através de uma espontaneidade, é possível falar sobre assuntos sérios, sendo esta uma forma facilitadora. Considerando que a população masculina costuma comunicar-se através da cultura de pares, ou seja, entre eles mesmos com temas referentes à saúde como cuidado, prevenção, ISTs e outros assuntos que, para o homem, fora do ciclo masculino, podem ser considerados constrangedores. O desafio é que, através de uma forma espontânea, possa-se alcançar o objetivo, ou seja, fazer uma reeducação entre os homens sobre o cuidado com sua saúde e a existência da PNAISH, uma vez que o homem pertence a um público fragilizado e de difícil acesso aos seus direitos.

Segundo Ferreira et al. (2016), estudos comprovados apontam que homens não buscam cuidar da sua saúde, além disso, não procuram sequer ajuda de um profissional especializado. Para o homem, cuidar do corpo é uma característica feminina, por esse mesmo motivo, pode-se dizer que a maioria nem saiba que 
existem políticas voltadas à saúde masculina, e só procuram por um médico quando a doença já se encontra em estado mais avançado, ou ainda, quando não estão mais possibilitados a trabalhar para nutrir a sua família, tornando-os ainda mais distantes da sua política. Conforme Solano et al. (2017), o homem não adere à atenção primária de saúde pelo seu próprio papel desempenhado perante a sociedade, que se relaciona de modo direto com as temáticas de gênero. Sendo assim, pelo fato de o homem não buscar cuidados, esse fator ocasiona sérios prejuízos, mantendo a desinformação, criando barreiras para que a sua própria política seja lançada ao meio masculino.

Em concordância com Carneiro et al. (2016), o fato de a população masculina procurar menos pelos serviços de saúde está ocasionando um aumento significativo na morbimortalidade desta população, influenciando de forma direta a falta da qualidade de saúde para o homem, sendo este um fato também desconhecido pelo homem. Os mesmos autores acreditam que a falta de preparação dos profissionais da saúde e a imobilidade das políticas públicas de saúde estão colaborando significativamente para a ausência do homem nos cuidados com a sua saúde, compreendendo que é função da equipe multidisciplinar apoiar e lançar a PNAISH na sociedade, por isso, nasce a necessidade de criar estratégias para o descobrimento do homem acerca da política.

De acordo com Solano et al. (2017), o conjunto de orientações do Sistema Único de Saúde (SUS) preconiza a igualdade e a integralidade do trabalho desenvolvido na saúde, no entanto, assume que a população masculina necessita que os profissionais da saúde tenham conhecimento diversificado e completo, dando ênfase à questão de gênero, de modo que busque entender a evolução histórica do homem e o surgimento de doenças, onde estes, por sua vez, merecem uma atenção especial. Os homens possuem o costume de enxergar a saúde pública como um âmbito feminino, que, na maioria das vezes é frequentado, por mulheres e os profissionais também, em sua maioria, são compostos pelo sexo feminino. Sendo assim, esse fato abre espaço para os homens acreditarem que não pertencem àquele espaço e, portanto, criam certa resistência.

Conforme Moreira et al. (2016), apesar de poucos homens terem conhecimento a respeito da PNAISH, isso não basta para que procurem cuidar da 
sua saúde. Desta forma, os profissionais de saúde buscam estratégias para atrair os homens para que não percam a oportunidade de prevenir doenças, e até conquistálos para que possam buscar cuidar da sua saúde. Algumas maneiras de criar oportunidades para o homem aproximar-se dos serviços de saúde são através da realização de exames clínicos rotineiros, tentativas de inclui-los no planejamento familiar e na valorização da paternidade.

\section{CONSIDERAÇÕES FINAIS}

Acerca do que foi pesquisado, compreende-se e torna-se claro o desconhecimento do público masculino acerca da sua política e a urgência em conscientizar os homens sobre a importância do cuidado com a sua saúde. O fato de o homem resistir aos cuidados afeta a saúde pública do país, que busca políticas públicas para tentar melhorar o contexto atual. É importante ressaltar que, além da necessidade do homem buscar por essa assistência, é importante também o conhecimento e a inovação de estratégias dos profissionais da saúde para tornar a Politica Nacional de Atenção Integral à Saúde do Homem conhecida e utilizada no meio masculino.

\section{REFERÊNCIAS BIBLIOGRÁFICAS}

AMARAL, Alice Mayra Santiago et al. Adolescência, gênero e sexualidade: uma revisão integrativa. Revista Enfermagem Contemporânea, v. 6, n. 1, p. 62-67, 2017. doi: http://dx.doi.org/10.17267/2317-3378rec.v6i1.1114.

ARRUDA, Guilherme Oliveira de; MATHIAS, Thais Aidar de Freitas; MARCON, Sonia Silva, Prevalência e fatores associados à utilização de serviços públicos de saúde por homens adultos. Ciênc. Saúde coletiva. v. 22, n. 1, p. 279-290, 2017. doi: http://dx.doi.org/10.1590/1413-81232017221.20532015.

AGUIAR, Ricardo Saraiva; SANTANA, Daniele de Carvalho; SANTANA, Patrícia de Carvalho. A percepção do enfermeiro da estratégia saúde da família sobre a saúde do homem, $\mathbf{R}$. Enferm. Cent. O. Min. v. 5, n. 3, p. 1844-1854, 2015. doi: http://dx.doi.org/10.19175/recom.v5i3.872.

CARNEIRO, Liana Maria Rocha et al. Atenção integral à saúde do homem: um desafio na atenção básica. Revista Brasileira em promoção da saúde. v. 29, n. 4, p. 554-563, 2016. 
CHAKORA, Eduardo Schwarz. Politica Nacional de Atenção Integral à Saúde do homem. Esc. Anna Nery. v. 18, n. 4, p. 559-561, 2014. doi: http://dx.doi.org/10.5935/1414-8145.20140079.

FERREIRA, Jaqueline Inácio Correia et al. Políticas públicas de atenção integral a saúde do homem: desafios para a enfermagem. Revista de Enfermagem da UERJ, 2016.

MINISTÉRIO DA SAÚDE. Perfil da morbimortalidade masculina no Brasil, Editora Saúde, 2018.

Disponível em: $<$ http://portalarquivos2.saude.gov.br/images/pdf/2018/novembro/07/Perfil-da-morbimortalidademasculina-no-Brasil.pdf>.

MOREIRA, Martha Cristina Nunes; GOMES, Romeu; RIBEIRO, Claudia Regina. E agora o homem vem?! Estratégias de atenção à saúde dos homens, Cad. Saúde Pública. v. 32, n 4, e00060015, 2016. doi: http://dx.doi.org/10.1590/0102-311X00060015.

MOREIRA, Michelle Araújo; CARVALHO, Camila Nunes. Atenção Integral à Saúde do Homem: Estratégias utilizadas por Enfermeiras (os) nas Unidades de Saúde da Família do interior da Bahia. Sal. \& Transf. Soc. v. 7, n. 3, p. 121-132, 2016.

MINISTERIO DA SAÚDE. Política Nacional de Atenção Integral da Saúde do homem princípios e diretrizes. Brasília: Editora Brasil, 2009. Disponível em: <http://www.unfpa.org.br/Arquivos/saude_do_homem.pdf>.

OLIVEIRA, Annelissa Andrade Virgínio de et al. Maus-tratos a idosos: revisão integrativa da literatura. Rev. bras. enferm. v. 66, n. 1, p. 128-33, 2013. doi: http://dx.doi.org/10.1590/S003471672013000100020 .

SOLANO, Lorrainy da Cruz et al. O acesso do homem ao serviço de saúde na atenção primária. Revista online de pesquisa, Rio de Janeiro. v. 9, n. 2, p. 2017. doi: http://dx.doi.org/10.9789/2175-5361.2017.v9i2.302-308.

SILVA, Vanessa Costa e; BARBOSA, Pedro Ribeiro; HORTELA, Virgínia Alonso. Parcerias na saúde: as organizações sociais como limites e possibilidades na gerencia da estratégia saúde da família. Ciênc. saúde coletiva. v. 21, n. 5, p. 1365-1375, 2016 . doi: http://dx.doi.org/10.1590/1413-81232015215.23912015. 